\title{
A method to preserve trends in quantile mapping bias correction of climate modeled temperature
}

\author{
Manolis G. Grillakis ${ }^{1}$, Aristeidis G. Koutroulis ${ }^{1}$, Ioannis N. Daliakopoulos ${ }^{1}$, and Ioannis K. Tsanis ${ }^{1,2}$ \\ ${ }^{1}$ Technical University of Crete, School of Environmental Engineering, Chania, Greece \\ ${ }^{2}$ McMaster University, Department of Civil Engineering, Hamilton, ON, Canada
}

Correspondence to: Manolis G. Grillakis (manolis@hydromech.gr)

Received: 30 May 2017 - Discussion started: 7 June 2017

Revised: 30 August 2017 - Accepted: 15 September 2017 - Published: 28 September 2017

\begin{abstract}
Bias correction of climate variables is a standard practice in climate change impact (CCI) studies. Various methodologies have been developed within the framework of quantile mapping. However, it is well known that quantile mapping may significantly modify the long-term statistics due to the time dependency of the temperature bias. Here, a method to overcome this issue without compromising the day-to-day correction statistics is presented. The methodology separates the modeled temperature signal into a normalized and a residual component relative to the modeled reference period climatology, in order to adjust the biases only for the former and preserve the signal of the later. The results show that this method allows for the preservation of the originally modeled long-term signal in the mean, the standard deviation and higher and lower percentiles of temperature. To illustrate the improvements, the methodology is tested on daily time series obtained from five Euro CORDEX regional climate models (RCMs).
\end{abstract}

\section{Introduction}

Climate model output provides the primary source of information used to quantify the effect of the foreseen anthropogenic climate change on natural systems. One of the most common and technically sound practices in climate change impact (CCI) studies is to calibrate impact models using the most suitable observational data and then to replace them with the climate model data in order to assess the effect of potential changes in the climate regime. Often, raw climate model data cannot be used in CCI models due to the presence of biases in the representation of regional climate (Christensen et al., 2008; Haerter et al., 2011). In fact, hydrological CCI studies outcome have been reported to become unrealistic without a prior adjustment of climate forcing biases (Hagemann et al., 2013; Hansen et al., 2006; Harding et al., 2014; Sharma et al., 2007). Papadimitriou et al. (2017) quantified the effect of the bias in seven forcing parameters on the resulting runoff of a land surface model, emphasizing the necessity of bias adjustments beyond the precipitation and temperature parameters. These biases are attributed to a number of reasons such as the imperfect representation of the physical processes within the model code and the coarse spatial resolution that does not permit the accurate representation of small-scale processes. Furthermore, in some cases, climate model tuning for global projections focuses on the adequate representation of feedbacks between processes, and hence the realistic depiction of a variable, such as temperature, against observations is sidelined (Hawkins et al., 2016).

A number of statistical bias correction methods have been developed and successfully applied in CCI studies (e.g., Grillakis et al., 2013; Haerter et al., 2011; Ines and Hansen, 2006; Teutschbein and Seibert, 2012). Their main task is to adjust the statistical properties of climate simulations to resemble those of observations, in a common climatological period. A commonly used type of procedure to accomplish this is a transfer function (TF) which minimizes the difference between the cumulative density function (CDF) of the climate model output and that of the observations, a process also referred to as quantile mapping. As a result of quantile mapping, the reference (calibration) period's adjusted data are statistically closer, and sometimes near-identical to the observations. Hence, the statistical outcome of an impact model 
run using observational data is likely to be reproduced by the adjusted data. The good performance of statistical bias correction methods in the reference period is well documented (Grillakis et al., 2011, 2013; Ines and Hansen, 2006; Papadimitriou et al., 2015). The procedure, however, overlooks the time dependency of the distribution and hence the unequal effect of the TF to the varying over time CDF. An indicative example is presented in Fig. 1, where modeled temperature data have a mean bias of $2.49^{\circ} \mathrm{C}$ in the reference period (Fig. 1a) relative to the observations. This mean bias is expressed by the average horizontal distance between the TF and the bisector of the central plot. The left histogram illustrates the reference period modeled data for 1981-2010. The histogram at the bottom is derived from observational data. The histogram on the right is derived from a moving 30-year period between 1981 and 2098. The rightmost histogram shows the difference between the reference period and the moving 30 -year period. The red mark shows the theoretical change in the average correction applied by the TF, due to the changes in the projected temperature histogram. Hence, the average correction applied for the period 2068 2097 reaches $3.85^{\circ} \mathrm{C}$, significantly higher than the reference period's bias (Fig. 1b). The time-dependency of the correction magnitude introduces a long-term signal distortion in the corrected data. In the quantile-mapping-based correction methodologies in which the TF distance from the bisector is variable, this effect is unavoidable. Nevertheless, in cases where the TF retains a relatively constant distance to the bisector (i.e., parallel to the bisector), the trend of the corrected data remains similar to the raw model data regardless of the temporal change in the model data histogram.

Based on the previous example, the time extrapolation of the TF is regarded as a leap of faith that may lead to a false certainty about the robustness of the adjusted projection. This may significantly change the original modeled long-term trend or other higher moments of the climate variable statistics that eventually change the long-term signal of the climate variable. In their work on distribution-based scaling (DBS) bias correction, Olsson et al. (2015) showed that their methodology might alter the long-term temperature trends, attributing the phenomenon in the severity of the biases in the mean or the standard deviation between the uncorrected temperatures and the observations. Maraun (2016) discusses whether the change in the trend is a desired feature of bias correction, concluding that it is case-specific and depends on the skillfulness of the climate model to simulate the correct long-term signal. In the case of CCI studies, this implies that climate model data are assessed for their skill to well represent the trend, which is not a common practice. A possible but indirect solution to this is described in Maurer and Pierce (2014), who study the change in precipitation trend over an ensemble of atmospheric general circulation model (AGCM). They conclude that, while individual quantile-mapping-corrected AGCM data may significantly modify the signal of change, a relatively large ensemble es-

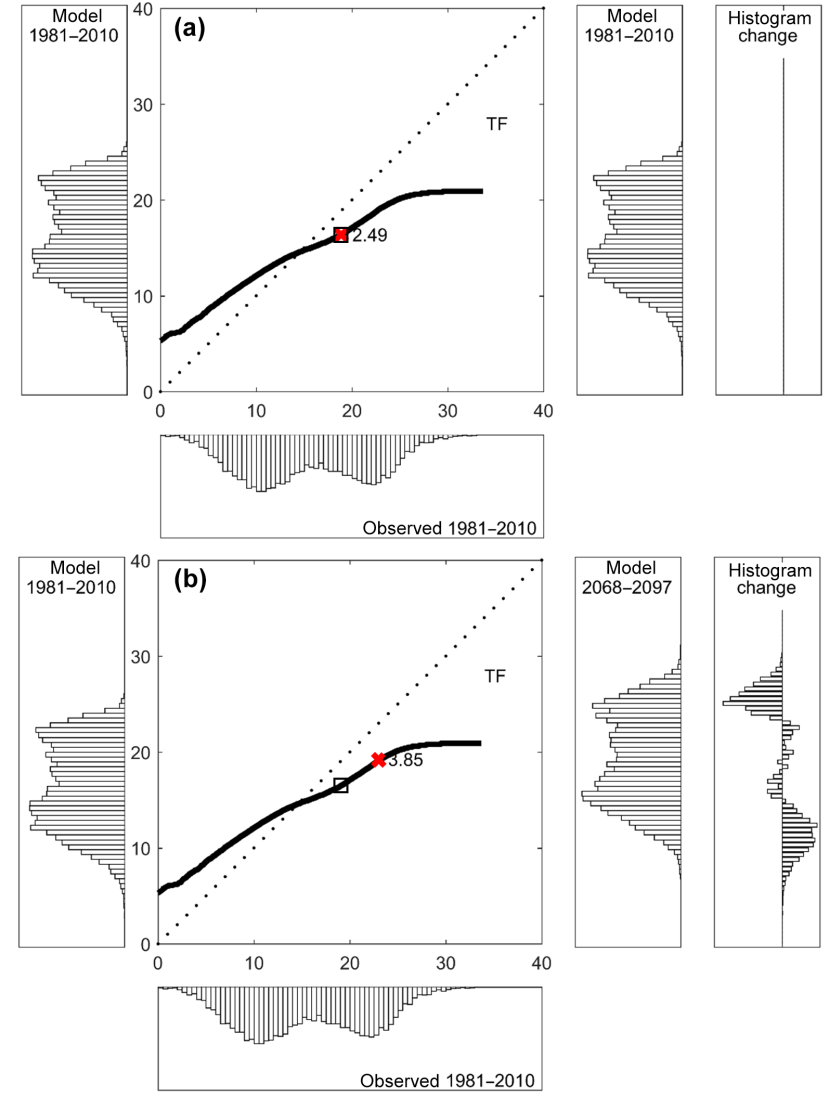

Figure 1. The transfer function (TF - heavy black line) between observed (bottom histograms) and modeled (histograms on the left) for the reference period (1981-2010) is used to adjust bias of a 30-year moving window from 1981-2010 to 2068-2097. The rightmost plot shows the residual histogram after bias correction. The change in the average correction (red mark) on the TF in comparison to the reference period mean correction (square) is shown. The animated version provided in the Supplement shows the temporal evolution of the bias as the 30-year time window moves on the projection data. Data were obtained from ICHEC-ECEARTH r12i1p1 SMHI-RCA4_v1 RCM of Euro-CORDEX experiment $\left(0.11^{\circ}\right.$ resolution) simulation under the representative concentration pathway of RCP85, for the location Chania International Airport (long $=24.08$, lat $=35.54$ ). Observational data were obtained from the E-OBS v14 dataset (Haylock et al., 2008) of $0.25^{\circ}$ spatial resolution.

timation diminishes the problem as individual model trend changes were canceled out. Li et al. (2010) present a quantile mapping method to adjust temperature biases taking into account the differences of the future and reference period distributions. A drawback of the method is that the difference between the two periods' distributions depends on the future period length. In their work, Hempel et al. (2013) propose a methodology to resolve the trend changing issue by preserving the absolute changes in monthly temperature and relative changes in monthly values of precipitation. A characteristic of their approach is that it maps anomalies instead of absolute 
values, indicating that specific correction values are attached to each temperature anomaly, while it also has the drawback that the edges of the distribution are not corrected adequately. A similar approach that is additive for temperature and multiplicative for precipitation was also followed by Pierce et al. (2015). Bürger et al. (2013) and Cannon et al. (2015) test the de-trending of the data prior to their quantile mapping correction, figuring that the removal of the trends prior to the quantile mapping and their reintroduction after the correction tends without absolutely maintaining the long-term trend.

In this study, we present a methodology to conserve the long-term statistics such as trend and variability of the climate model data in quantile mapping. The methodology considers the separation of the temperature signal relative to the raw data reference period, producing a normalized and a residuals data stream. The separation is performed on an annual basis. The residuals include the gradual changes in the signal and the year-to-year fluctuations in the distribution of the temperature. The quantile mapping bias correction is then applied to the normalized daily temperature. Finally, the residual components are merged to the bias-corrected time series to form the corrected time series. The idea of identifying and using two different timescales in bias correction of temperature was introduced in Haerter et al. (2011), who present a method to separate the different timescales and apply a correction to each one. The methodology presented here is tested along with a generalized version of the multisegment statistical bias correction (MSBC) quantile mapping methodology (Grillakis et al., 2013). The methodology takes the form of a pre- and post-processing module that can be applied along with different statistical bias correction methodologies. The two-step procedure is examined for its ability to remove the daily biases with simultaneous preservation of the long-term statistics. The procedure is compared to the simple quantile mapping and a quantile mapping in combination with a simpler trend preservation procedure.

\section{Methods}

\subsection{Residual separation}

The statistical difference of each individual year's simulated data, compared to the average reference period simulated data is identified as residuals. These are estimated between the CDF of each year's modeled climate data and the CDF of the entire reference period of the model data. Let $S_{\mathrm{R}}$ be the reference period model data and $S_{i}$ the climate data for year $i$, then the normalized data $S_{i}^{\mathrm{N}}$ for year $i$ are estimated by transferring each year's data onto the average reference period CDF through a transfer function $\mathrm{TF}_{S_{i}}$ estimated annually. This can be formulated as Eq. (1).

$S_{i}^{\mathrm{N}}=\mathrm{TF}_{S_{\mathrm{R}}}^{-1}\left(\mathrm{TF}_{S_{i}}\left(S_{i}\right)\right)$

The difference between the original model data $S_{i}$ and the normalized data $S_{i}^{\mathrm{N}}$ is the residual components $S_{i}^{\mathrm{D}}$ of the time series (Eq. 2).

$S_{i}^{\mathrm{D}}=S_{i}-S_{i}^{\mathrm{N}}$

The original model data $S_{i}$ can be reproduced by adding back the residuals $S_{i}^{\mathrm{D}}$ to the normalized data $S_{i}^{\mathrm{N}}$. After the separation, the normalized climate model data are statistically bias-corrected following a suitable methodology. The residuals are preserved in order to be later added back to the biascorrected time series. We refer to the described method as a normalization module (NM) to hereafter lighten the nomenclature of the paper. The normalization procedure is performed on annual basis, as this consists of an obvious periodicity to use in the case of temperature, even if it is not so well defined in the tropics. The underlying assumption of the NM procedure is that it considers no major changes in the reference period data, a notion that can hardly fall short due to the usually short length of the reference period.

\subsection{Bias correction}

Here, the NM is applied along with a modification of the MSBC algorithm that is presented in Grillakis et al. (2013). This methodology follows the principles of quantile mapping correction techniques and was originally designed and tested for GCM precipitation adjustment. The method partitions the CDF data into discrete segments and an individual quantile mapping correction is applied to each segment, achieving a better-fitted transfer function. Here the methodology is modified to use linear functions instead of the gamma functions used in the original methodology, in order to facilitate potential negative temperature values but also as a known technique in quantile mapping, as it has also been used elsewhere (Themeß1 et al., 2011). An indicative example is shown in Fig. 2, where the CDFs are split into discrete segments and linear functions are fit to each of them. In Fig. 2, $p$ symbolizes the cumulative probability and $s$ is the slope of the linear function. Then the corrected temperature for each temperature value of the specific segment is estimated as in Eq. (3).

$T_{\mathrm{corr}}^{\mathrm{n}}=s_{\mathrm{obs}}^{\mathrm{n}} \cdot\left(\frac{T_{\mathrm{raw}}^{\mathrm{n}}-b_{\mathrm{raw}}^{\mathrm{n}}}{s_{\mathrm{raw}}^{\mathrm{n}}}\right)+b_{\mathrm{obs}}^{\mathrm{n}}$

The optimal number of segments is estimated using the Schwarz Bayesian information criterion (SBIC) to balance between complexity and performance. Additionally, the upper and lower edge segments are explicitly corrected using the average difference between the reference period of the raw model data and the observations (Fig. $2 \Delta T$ ). This provides robustness, avoiding unrealistic temperature values at the edges of the model CDF. The bias correction methodology modification has been already used in the Bias Correction Intercomparison Project (BCIP) (Nikulin et al., 2015), while produced adjusted data have been used in a number of CCI studies (Daliakopoulos et al., 2016; Grillakis et al., 2016; Koutroulis et al., 2016; Papadimitriou et al., 2017, 

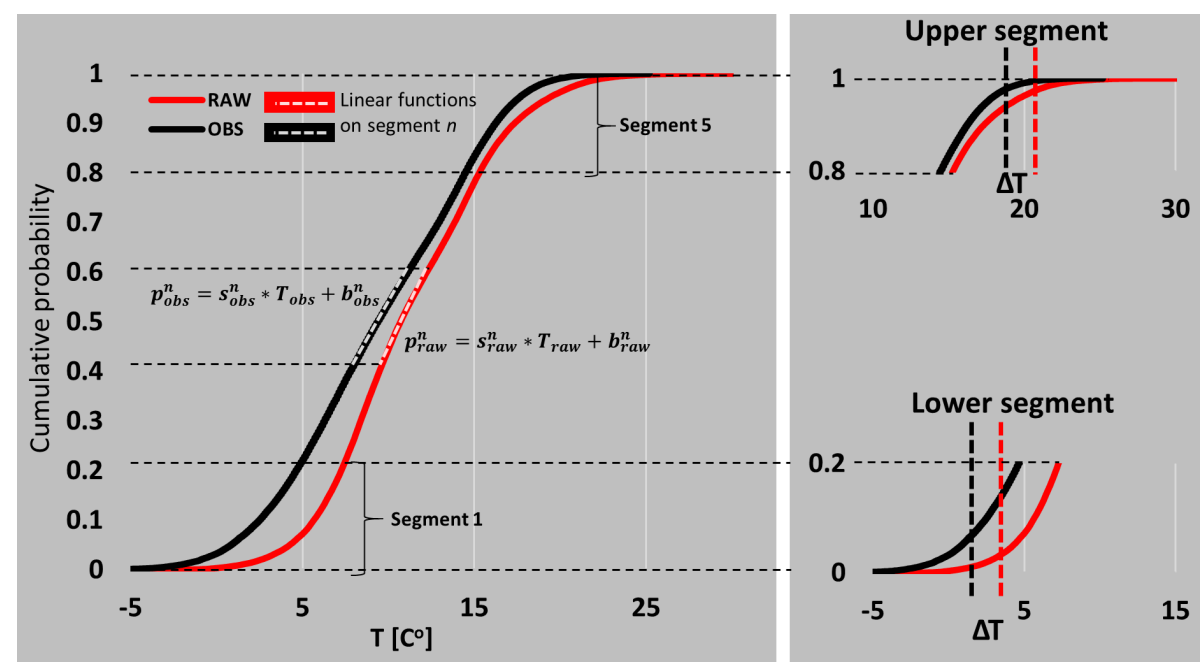

Figure 2. MSBC methodology on temperature correction using linear functions (borrowed from Grillakis et al., 2013; modified) in one of the data segments.

2016). As the MSBC methodology belongs to the parametric quantile mapping techniques, it shares their advantages and drawbacks. A comprehensive shakedown of advantages and disadvantages of quantile mapping in comparison to other methods can be found in Maraun et al. (2010) and Themeß1 et al. (2011). A step-by-step example of the multisegment correction procedure is provided in Appendix A of Grillakis et al. (2013).

\subsection{Validation of the results}

The Klemes (1986) split sample test methodology was adopted for verification. Split sample is the most common type of test used for the validation of model efficiency. The methodology considers two periods of calibration and validation between the observed and modeled data. The first period is used for the calibration, while the second period is used as a pseudo-future period in which the adjusted data are assessed against the observations. A drawback of the split sample test in bias correction validation operations is that the remaining bias of the validation period is a function of the bias correction methodology deficiency and the model deficiency itself to describe the validation period's climate, in aspects that are not intended to be bias-corrected. That said, a skillful bias correction method should deal well in that context, as model "democracy" (Knutti, 2010), i.e., the assumption that all model projections are equally possible, is common in CCI studies in which little attention is given to the model selection.

\section{Case study area and data}

To examine the effect of NM on the bias correction on a time series, the Hadley Centre Central England Temperature (HadCET - Parker et al., 1992) observational dataset was considered to adjust the simulated output from the earth system model MIROC-ESM-CHEM (Hasumi and Emori, 2004) historical emissions run between 1850 and 2005 for central England. This particular case study was chosen due to the large observational record (the longest instrumental record of temperature in the world) that is available for central England, i.e., the triangular area of the United Kingdom enclosed by Lancashire, London and Bristol. Discussion about dataset-related uncertainties can be found in Parker et al. (1992) and Parker and Horton (2005). In the specific application and in order to resemble a typical CCI study, data between 1850 and 1899 serve as the calibration period, while the rest of the data between 1900 and 2005 are used as the pseudo-future period for the validation. Finally, the bias correction results of the two procedures, with (BC$\mathrm{NM}$ ) and without (BC) the normalization module, were compared against the validation period observations. An additional comparison was also performed to a less complicated trend preservation procedure, inspired by Bürger et al. (2013) and Cannon et al. (2015). This procedure considers the detrending of the raw data using a 5-year moving average temperature. The detrended data are corrected using the BC methodology, while the trend is additively put back into the time series after the correction, similarly to the NM. We refer to this as BC-TREND. This comparison is used to benchmark the BC-NM towards a simpler quantile mapping that also approaches the trend preservation.

Furthermore, to expand the methodology assessment on the regional scale, the split sample test is adopted to assess 
Table 1. RCMs used in this experiment.

\begin{tabular}{ll}
\hline$\#$ & $\{\mathrm{GCM}\}$ _\{realization\}_\{RCM $\}$ \\
\hline 1 & CNRM-CM5_r1i1p1_SMHI-RCA4_v1 \\
2 & EC-EARTH_r12i1p1_SMHI-RCA4_v1 \\
3 & EC-EARTH_r3i1p1_DMI-HIRHAM5_v1 \\
4 & IPSL-CM5A-MR_r1i1p1_SMHI-RCA4_v1 \\
& RCA4_v1RCA4_v1RCA4_v1 \\
5 & MPI-ESM-LR_r1i1p1_SMHI-RCA4_v1 \\
\hline
\end{tabular}

the efficiency of the two procedures on a pan-European scale. In order to scale up the split sample test, the $k$-fold cross validation test (Geisser, 1993) is employed. The procedure has been proposed for evaluating the performance of bias correction procedures in Maraun (2016). In the $k$-fold cross validation test, the data are partitioned into $k$ equal sized folds. Of the $k$ folds, one subsample is retained each time as the validation data for testing the model, and the remaining $k-1$ subsamples are used as calibration data. In a final test, the procedures are applied on a long-term transient climate projection experiment to assess their effect in the long-term attributes of the temperature in a European-scale application.

Temperature data from the European division of the Coordinated Regional Downscaling Experiment (CORDEX), openly available through the Earth System Grid Federation (ESGF), are considered. Additional information about the Euro CORDEX domain can be found on the CORDEX web page (http://wcrp-cordex.ipsl.jussieu.fr/). Data from five regional climate models (RCMs) (Table 1) with $0.44^{\circ}$ spatial resolution and daily time step between 1951 and 2100 are used. The projection data are considered under Representative Concentration Pathway (RCP) 8.5, which projects an $8.5 \mathrm{~W} \mathrm{~m}^{-2}$ average increase in the radiative forcing until 2100. The European domain CORDEX simulations have been evaluated for their performance in previous studies (Kotlarski et al., 2014; Prein et al., 2015). The EOBSv12 temperature data were used (Haylock et al., 2008). Discussion about the applicability of EOBS to compare temperature of RCMs control climate simulations can be found in Kyselý and Plavcová (2010). Figure 3 shows the 1951-2005 daily temperature average and standard deviation for the five RCMs of Table 1. The RCMs' mean bias ranges between about -2 and $1{ }^{\circ} \mathrm{C}$ relative to the EOBS dataset (individual models data are included to the ESM). The positive mean bias in all RCMs is mainly seen in eastern Europe, while the same areas exhibit negative bias in standard deviation. Some of the bias may, however, be attributed to the ability of the observational dataset to represent the true temperature (Hofstra et al., 2010).

For the $k$-fold cross validation, the RCM data between 1951 and 2010 are split into six 10-year sections, comprising a 6-fold, five-RCM-ensemble experiment of Fig. 4. Each section is validated once by using the remaining five sections

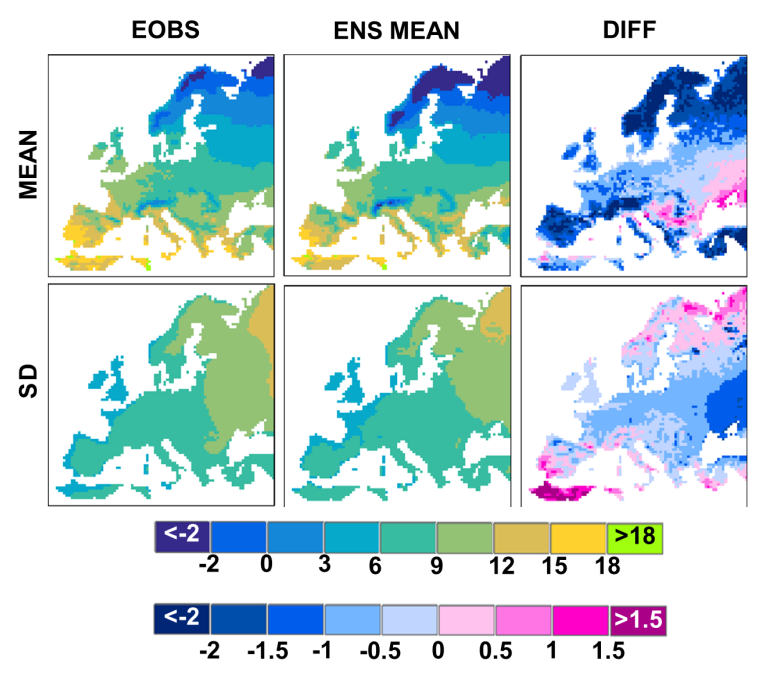

Figure 3. Mean temperature (upper) and standard deviation (lower) for EOBS, RCM ensemble (ENS) and for their difference (model obs) (DIFF) for the reference period 1951-2005.

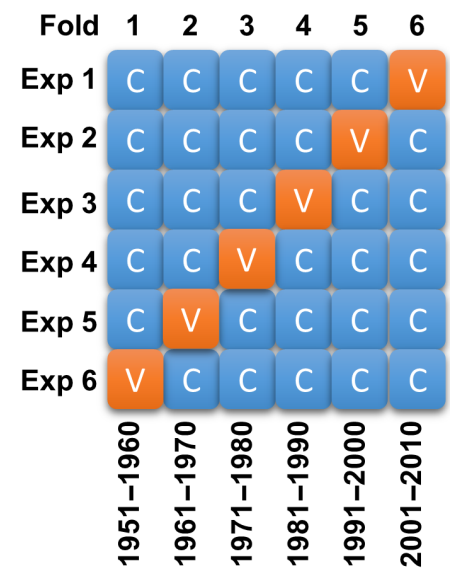

Figure 4. The 6-fold cross validation scheme with the calibration (C) and the validation (V) periods of each fold. Each experiment (Exp) was replicated for all five RCMs.

for the calibration. A total of 30 tests are conducted using each procedure.

For the transient experiment, the RCM data between 1951 and 2100 are considered, using the 1951-2010 as calibration to correct the 1951-2100 data.

\section{Results}

The results of the split sample test on the central England example are presented in Fig. 5. The NM separates of the raw data into a residuals and a normalized stream (Fig. 5b). In the annual aggregates the normalized time series do not exhibit any trend or significant fluctuation, since the normalization is performed on annual basis, while the long-term trend and variability are contained in the residual time series. In Fig. 5a, 
Table 2. Statistical properties of the calibration and the validation periods for the two bias correction procedures. Variables denoted with * are estimated on annual aggregates. SD stands for standard deviation, $\mathrm{p} n$ for the $n$th quantile and IQR for the interquartile range.

\begin{tabular}{|c|c|c|c|c|c|c|c|c|}
\hline & Parameter & RAW & Normalized & Residuals & OBS & $\mathrm{BC}$ & BC-NM & $\mathrm{BC}_{\text {TREND }}$ \\
\hline \multirow{7}{*}{ 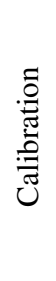 } & Mean $\left({ }^{\circ} \mathrm{C}\right)$ & 11.2 & 11.2 & 0.0 & 9.1 & 9.2 & 9.2 & 9.1 \\
\hline & $\mathrm{SD}\left({ }^{\circ} \mathrm{C}\right)$ & 4.5 & 4.6 & 0.9 & 5.3 & 5.3 & 5.3 & 5.3 \\
\hline & $\mathrm{p} 10\left({ }^{\circ} \mathrm{C}\right)$ & 5.7 & 5.7 & -0.9 & 2.1 & 2.2 & 2.2 & 2.1 \\
\hline & $\mathrm{p} 90\left({ }^{\circ} \mathrm{C}\right)$ & 17.4 & 17.2 & 1.0 & 16.3 & 16.3 & 16.2 & 16.2 \\
\hline & Slope $\left({ }^{\circ} \mathrm{C} 10 \text { years }{ }^{-1}\right)^{*}$ & -0.067 & 0.000 & -0.067 & -0.026 & -0.086 & -0.065 & -0.061 \\
\hline & $\mathrm{SD}\left({ }^{\circ} \mathrm{C}\right)^{*}$ & 0.46 & 0.46 & 0.01 & 0.61 & 0.57 & 0.45 & 0.53 \\
\hline & $\mathrm{IQR}^{*}$ & 0.76 & 0.76 & 0.01 & 0.86 & 0.95 & 0.75 & 0.94 \\
\hline \multirow{7}{*}{ 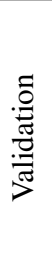 } & Mean $\left({ }^{\circ} \mathrm{C}\right)$ & 11.3 & 11.2 & 0.1 & 9.6 & 9.3 & 9.3 & 9.2 \\
\hline & $\mathrm{SD}\left({ }^{\circ} \mathrm{C}\right)$ & 4.7 & 4.6 & 0.9 & 5.2 & 5.5 & 5.4 & 5.5 \\
\hline & $\mathrm{p} 10\left({ }^{\circ} \mathrm{C}\right)$ & 5.6 & 5.7 & -0.9 & 2.7 & 2.0 & 2.0 & 1.9 \\
\hline & $\mathrm{p} 90\left({ }^{\circ} \mathrm{C}\right)$ & 17.4 & 17.2 & 1.0 & 16.3 & 16.3 & 16.2 & 16.2 \\
\hline & Slope $\left({ }^{\circ} \mathrm{C} 10 \text { years }{ }^{-1}\right)^{*}$ & 0.052 & 0.000 & 0.051 & 0.076 & 0.062 & 0.051 & 0.044 \\
\hline & $\mathrm{SD}\left({ }^{\circ} \mathrm{C}\right)^{*}$ & 0.48 & 0.47 & 0.01 & 0.54 & 0.57 & 0.46 & 0.53 \\
\hline & $\mathrm{IQR}^{*}$ & 0.63 & 0.62 & 0.01 & 0.76 & 0.75 & 0.62 & 0.68 \\
\hline
\end{tabular}
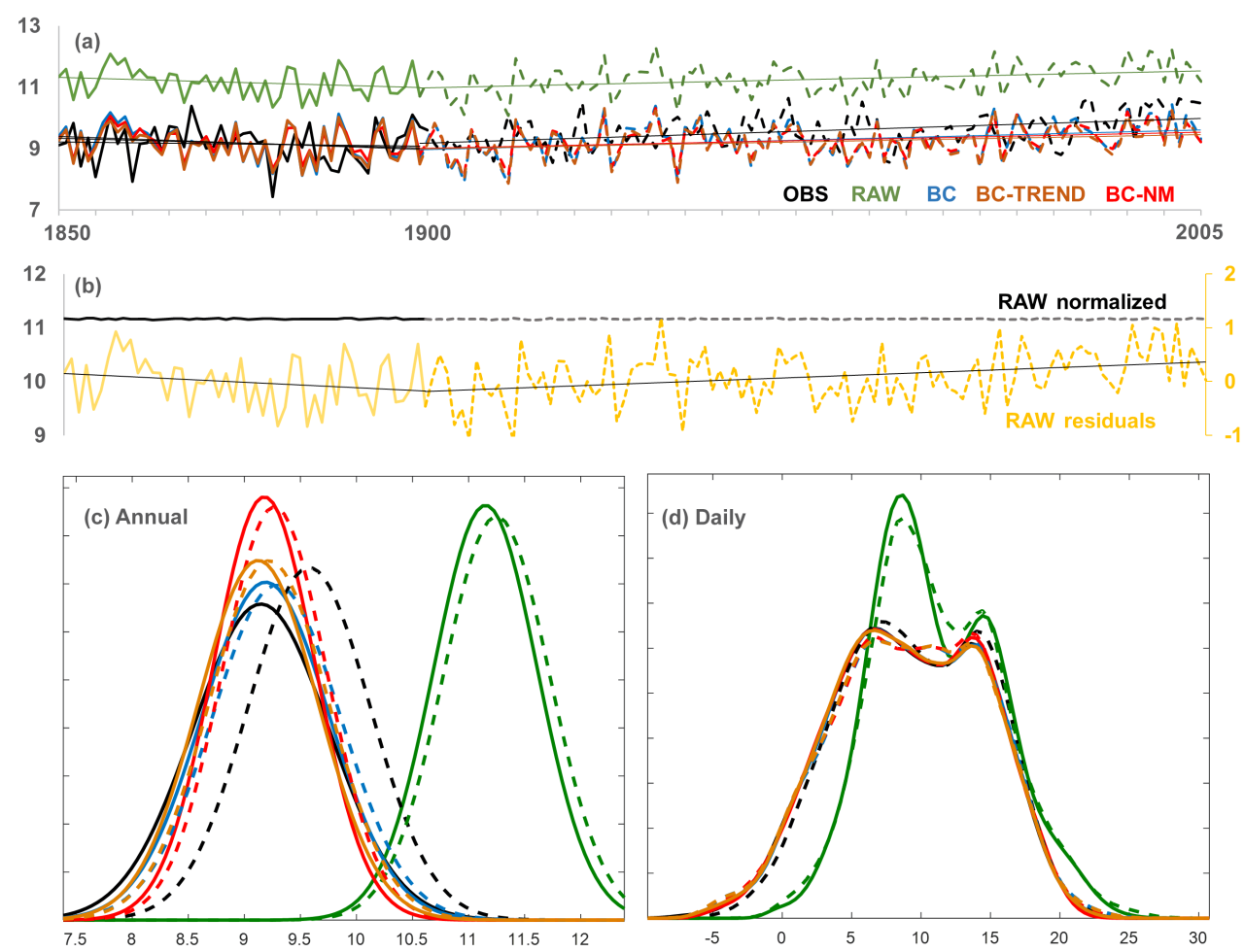

Figure 5. (a) Annual average temperature of raw model, observations and the bias-corrected with and without the NM data and following the BC-TREND approach, for the calibration period 1850-1899 (solid lines) and the validation period 1900-2005 (dashed lines). (b) Annual averages of the normalized and the residuals of the raw temperature. Probability densities of annual (c) and of daily means (d).

annual aggregates obtained via the $\mathrm{BC}, \mathrm{BC}-\mathrm{NM}$, and the $\mathrm{BC}$ TREND procedures are compared to the raw data and the observations. Results show that all three procedures adjust the raw data to better fit the observations in the calibration period $1850-1899$. In the validation period, all three procedures produce similar results in terms of mean and standard deviation, but the BC-NM long-term linear trend is slightly lower than that of the $\mathrm{BC}$ results and slightly higher than the respective BC-TREND slope. While both BC and BC-TREND slopes are closer to the observations' linear trend, the BC-NM is closer to the raw data trend (Table 2). The BC-TREND validation period trend is found lower relative to the RAW data, 

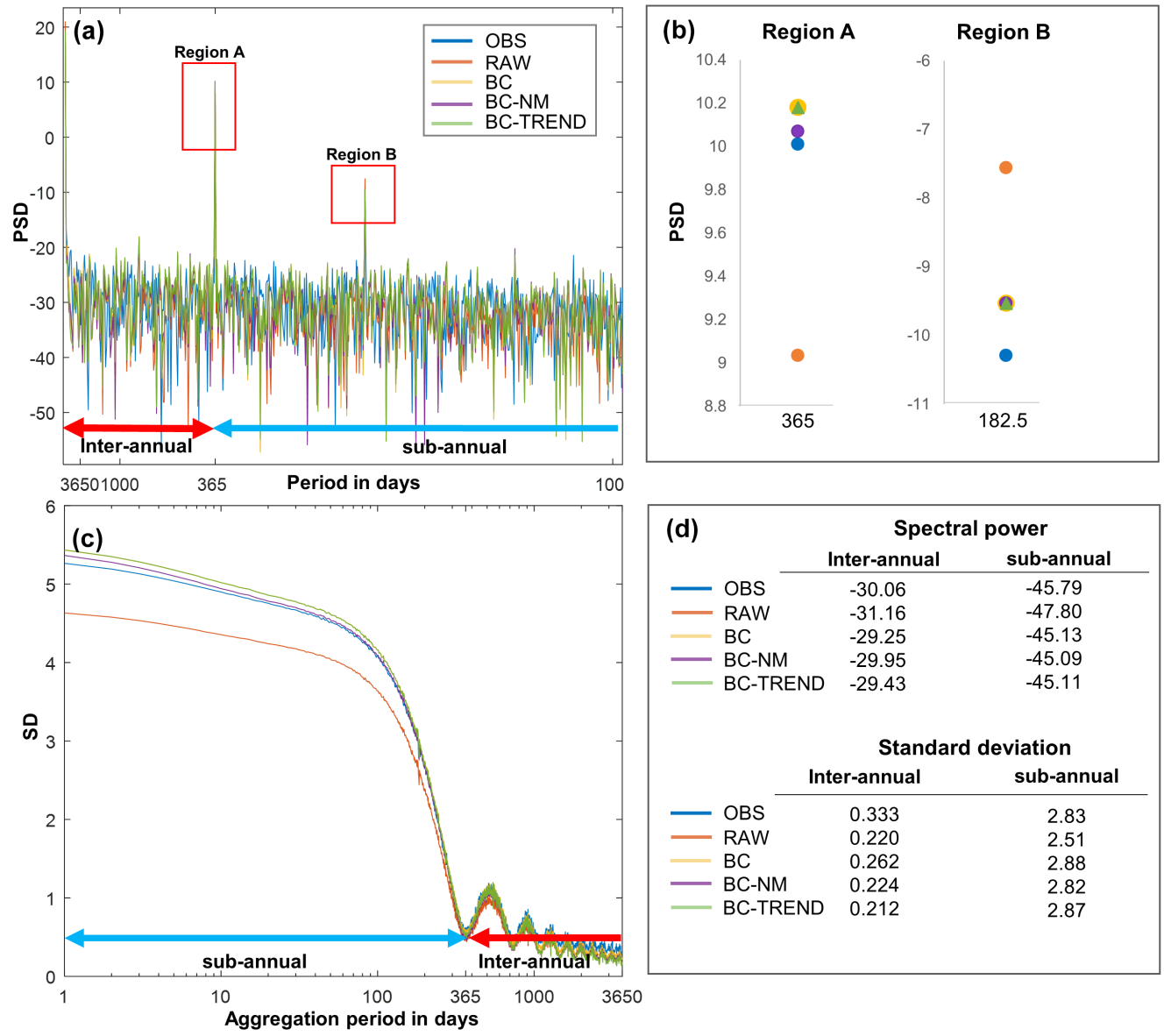

Figure 6. Power spectral density of temperature (a) and high-power regions of annual and half-year periods (b). (c) Standard deviation of temperature aggregates between 1 and 10957 days (horizontal axis visible between 1 day and 10 years). (d) The inter-annual and sub-annual periods' average (denoted with red and cyan arrows respectively) spectral power (a) and standard deviation (c).

but closer to it relative to the $\mathrm{BC}$. This is attributed to the new trend that was introduced to the detrended time series by the differential quantile mapping in each year's CDF, similar to the Fig. 1 example.

Figure $5 \mathrm{c}$ shows that, in the annual aggregated temperature, the BC-NM resembles the raw data histograms in shape, but shifted in mean towards the observations. A small decrease in the variability can also be observed in the BCNM relative to the raw data but consists of a substantially smaller disturbance relative to the BC. The annual variability in BC-TREND is closer to the raw data compared to the $\mathrm{BC}$ approach, but the BC-NM still outperforms in the annual variability preservation. The transfer of the mean with a simultaneous preservation of the larger part of the variability of the BC consists of a nearly idealized behavior for the adjusted data when the long-term statistics preservation is a desired characteristic, as the distribution of the annual temperature averages is retained after the correction (trend, standard deviation, interquartile range - Table 2). The respective results generated on daily data (Fig. 5d) show that all three procedures adjust the calibration and validation histograms to a similar degree towards the observations. This can also be verified by the mean, the standard deviation, and the 10th and 90th percentile of the daily data of Table 2 . An early concluding remark about the NM is that it retained the long-term statistics of the adjusted data towards the climate model signal better than the alternative approaches, without, however, sacrificing the daily scale quality of the correction.

To further inter-compare the effect of each approach in the data variability beyond the inter-annual and the daily basis, we estimate the power spectral density (PSD; Huybers and Curry, 2006) over their daily temperature signals (Fig. 6). The marked spectral peaks associated with the annual and 6month periodicity are an expected result. Focusing on those regions (Fig. 6b), it is shown that the BC-NM is closer to the observational variability relative to the other two correction techniques, while in the 6 months all techniques provide similar results. The average power density of the domain beyond the annual periodic shows that the BC-NM is closer to the raw data, while the respective sub-annual average is 

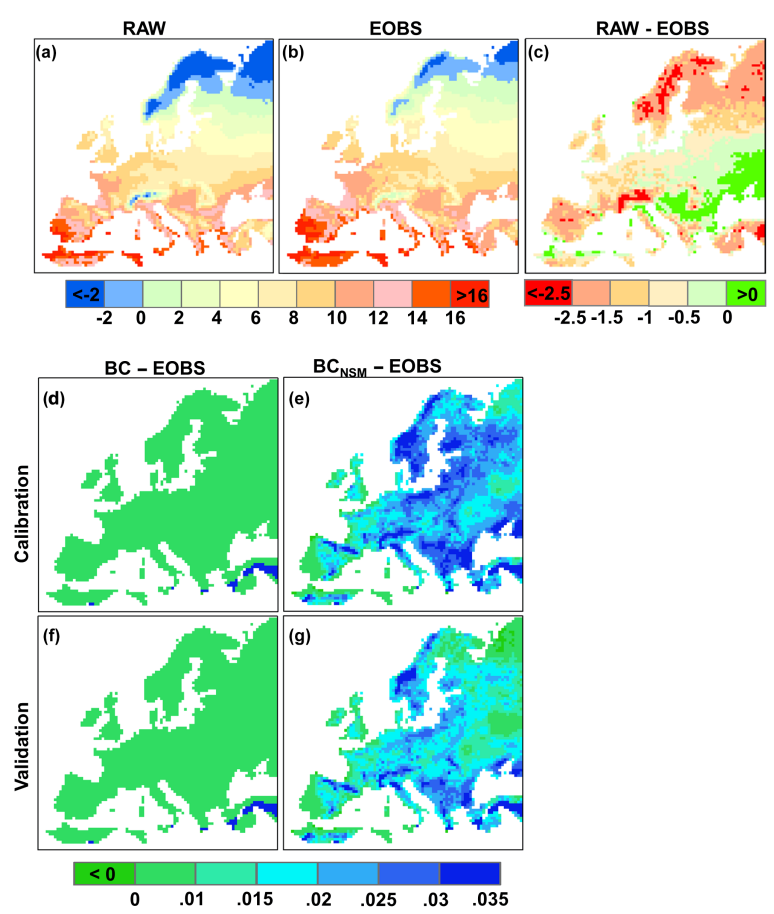

Figure 7. Mean surface temperature of the cross validation test. Panels (a) and (b) show the ensemble mean of the five raw models data and the EOBS respectively, while panel (c) shows their difference. Panels (d) and (e) show the ensemble mean remaining bias of the five RCMs after the correction with and without the NM module respectively, for the calibration periods' data. Panels (f) and (g) are the same as (d) and (e) but for the validation period data.

almost equal to the $\mathrm{BC}$ and the BC-TREND averages. Figure $6 \mathrm{c}$ shows the standard deviation estimated on temperature aggregates between 1 and 10957 days (i.e., 30 years). Figure $6 \mathrm{~d}$ shows the average variability and average spectral power of the two scaling regimes, above and below annual. The sub-annual scales average variability of the BC-NM resembles the observational variability, outperforming the $\mathrm{BC}$ and BC-TREND approaches that show higher values. More importantly, the NM works well on the inter-annual scale, where the average variability is found to be closer to the raw data variability compared to the inflated $\mathrm{BC}$ and the deflated BC-TREND results.

In Fig. 7, the results of the cross validation test of the $\mathrm{BC}$ on the Euro CORDEX data with and without the use of NM are shown, in terms of mean temperature. The means of the raw temperature data and the observations are respectively equal for their calibration and the validation periods due to the design of the experiment. The bias correction results show that both the correction with and without the NM, appropriately meet the needs in terms of the mean value. The differences between the calibration and validation averages with the corresponding observations show consistently low residuals. A significant difference between the two tests is

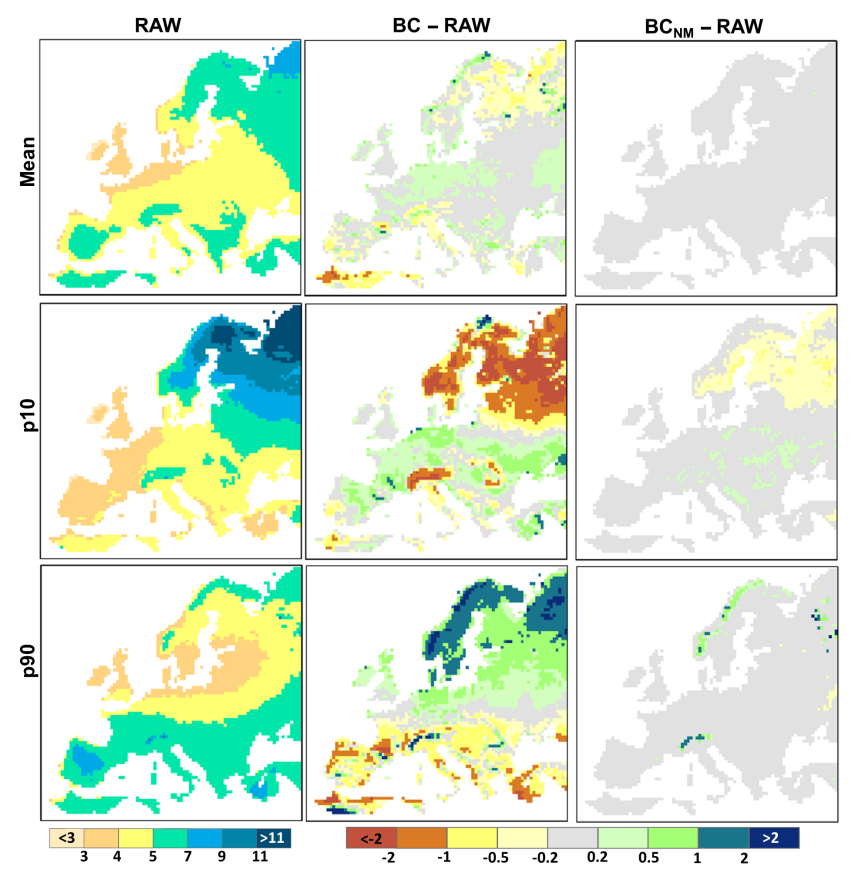

Figure 8. Ensemble long-term linear trend of the five RCMs' data. The trend is estimated on the mean temperature (top) and the 10th (middle) and 90th (bottom) percentiles on an annual basis. The change in the corrected data trend relative to the raw data trend is provided for the BC (middle panels) and the BC-NM data (right panels). All values are expressed as degrees per century $\left({ }^{\circ} \mathrm{C} 100\right.$ years $\left.^{-1}\right)$.

that the use of the BC-NM increases the residuals due to the exclusion of some parts of the signal from the correction process. Nonetheless, the scale of the residuals is considered below significance in the context of CCI studies, as it ranges only up to $0.035^{\circ} \mathrm{C}$. The increased residuals of the NM are the trade-off to the preservation of the model longterm climate change signal, in the transient experiment. Potential drawbacks that arise from the residuals' existence are discussed later. Figure 8 shows the long-term change in the signal of the mean temperature, for the 10th and 90th percentiles (estimated on annual basis). The trends are estimated by linear least squares regression and are expressed in degrees Celcius per century. The use of the NM was superior in preserving the long-term trend relative to the raw model data in all three cases. Without using the NM module, the distortion in the mean annual temperature trend lies between -0.5 and $0.5^{\circ} \mathrm{C}$ per century, while the distortion in the 10th and 90th percentiles is apparently more profound. Additionally, the northeastern Europe 10th and 90th percentiles reveal a widening of the temperature distribution when NM is not used. This widening is attributed to the considerable negative trend in the 10th percentile and the considerable positive 90th percentile trend in the same areas. The magnitude of the distortion is considerable and can potentially lead to CCI 

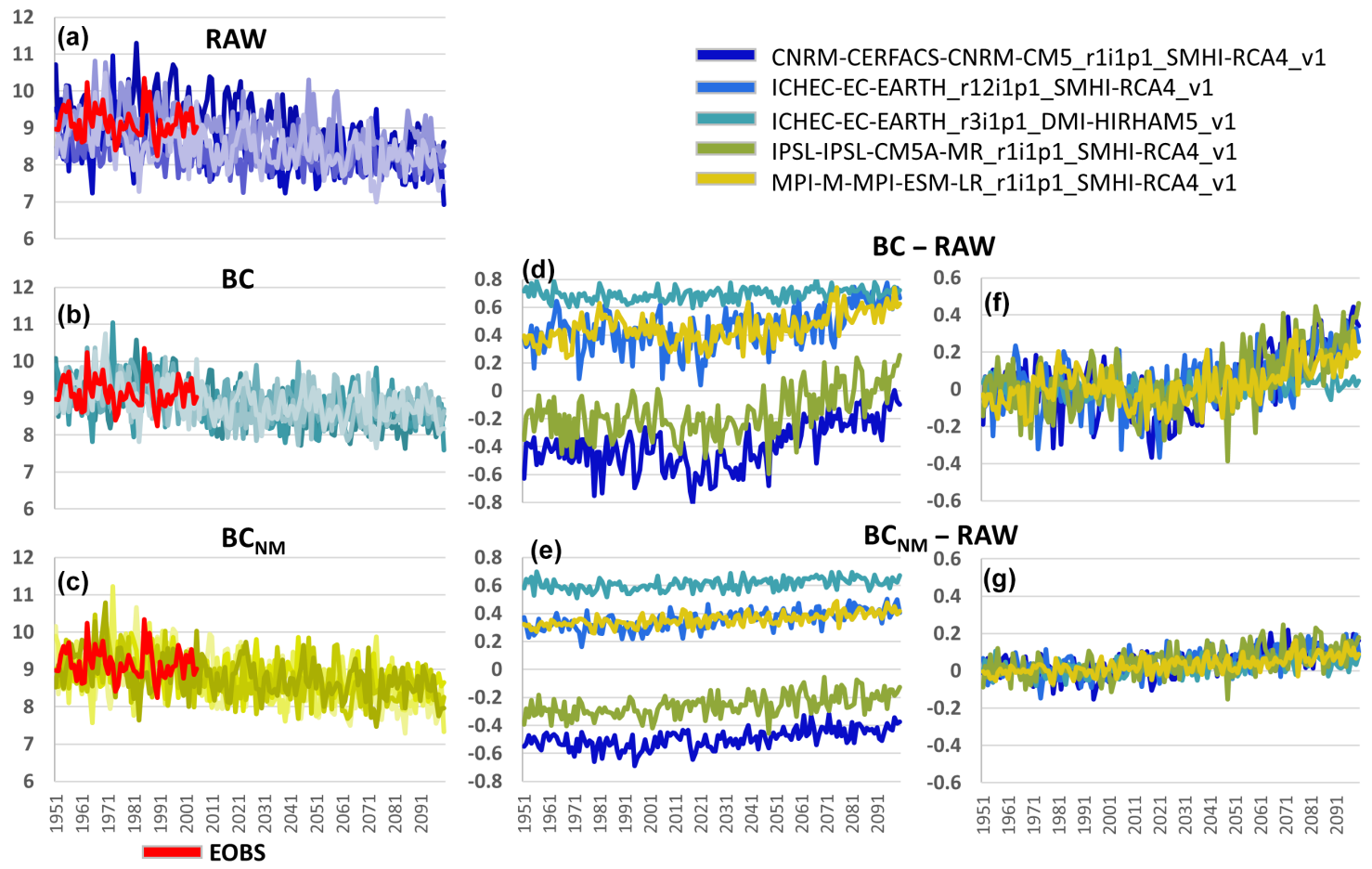

Figure 9. Average of standard deviations for the study domain, for the raw data (a), the BC (b) and the BC-NM (c) for the different models and the observations, on an annual basis. Differences between the raw and the bias-corrected standard deviations are shown in (d) and (e). Plots (f) and (g) correspond to the same data as (d) and (e), but normalized for their 1951-2005 mean.

overestimation. In contrast, with the use of NM the change in the trend is reduced in most of the European area.

The impact of NM on the standard deviation is also significant. Figure 9 shows the evolution of the standard deviations of the adjusted daily data for each model, in the cases of raw data and the bias-corrected data using the $\mathrm{BC}$ and the $\mathrm{BC}$ NM. The standard deviation is estimated for each grid point and calendar year, and is averaged across the study domain. The results show that the standard deviation of the adjusted data differs from the respective standard deviations of the raw data, in both adjustment approaches. This is an expected outcome, as raw model data standard deviations differ from the respective observed data standard deviation (Fig. 9d, e). However, the standard deviation differences between BCNM and the raw data (Fig. 9f) are significantly more stable than the respective differences from BC (Fig. 9g), meaning that the signal of standard deviation is better preserved and does not inflate significantly with time in the former case. Additionally, the variation of the standard deviations time series exhibits lower fluctuations.

\section{Discussion}

This study focuses on known issues of bias correction that have been well discussed in the literature. Whether the longterm signal of temperature should be preserved or not has been discussed on a more theoretical level in Maraun (2016), while Haerter et al. (2011) mention that a credible bias correction methodology should involve the consequences of greenhouse gas concentration changes. This is somehow consistent with the temperature trend preservation as the model sensitivity is retained in the corrected time series. As pointed in Fischer et al. (2012), models tend to underestimate the inter-annual variability due to deficiencies between landatmosphere interactions, which urges for its correction. Nevertheless, the long-term statistics' preservation may be necessitated in cases that temperature is used in biophysical impact modeling (Rubino et al., 2016), or may be preferred as a safer option than the unintentional alteration, especially in cases where the observational data record is not long enough.

The methodology shares similarities to other correction methods found in the literature. Furthermore it exhibits a number of advancements that overpass drawbacks of other trend preserving methodologies. The fundamental idea of the presented method is also identified in the method of Haerter et al. (2011) method that considers two different timescales and performs a cascade correction of temperature. In the present study, a discrimination of annual and daily scales is used for the separation of the temperature signal in two parts. While in the former methodology, the cascade correction benefits the results in both timescales, here the separation offers a correction on the daily scale and an intentional preservation of the raw model statistics on the annual scale. 
Comparisons can also be performed with the methodology of $\mathrm{Li}$ et al. (2010), who use the differences in the raw data between the reference period and the projection period. In the present study the differences are defined between the reference period and each year of correction separately. This can be considered as an evolution of the technique that overcomes the subjectivity of the future period selection. Additionally, the quantile mapping correction ensures the skillful correction in the higher and lower quantiles, relative to simpler additive approaches such as that of Hempel et al. (2013), which, while preserving the trend and year-to-year variability, marginally improves the tails of the temperature distribution (Sippel et al., 2016). Regarding the simpler BC-TREND version that was used for the central England example, it was found that it tends to preserve the long-term statistics as also noted by Cannon et al. (2015), but the 5-year average that was used for the trend preservation still cannot encompass the changes in each year's CDF, as the NM can.

Beyond these advancements, a critical drawback of the presented methodology is that it uses a large number of parameters to approximate the transfer functions in the two stages of the correction. The methodology can be described as of "varying complexity" as the number of the estimated parameters (number of segments) and the added value of the complexity is weighted by an information criterion. Nonetheless, it is highly invasive, which means that in the case that high-noise observations were used, it would lead to transfer of that noise to the corrected data variability. This was marginally detected in the analysis of the standard deviations in Fig. 9, even if the effect of the BC-NM mitigated the effect compared to the BC. Another weakness stems from the residuals' exclusion from the correction. In the theoretical case where the future projected temperature variability changes radically relative to the reference period, the correction would result in larger remaining biases as it was shown earlier, which could impair the physical continuity of the time series. This limitation should be taken into consideration for the case that the BC-NM is used to correct other types of variables, without forbidding its use on them.

\section{Conclusions}

This study elaborates the issue of the distortion of the longterm statistics in quantile mapping statistical bias correction relative to the raw model data. An extra processing step is presented that can be applied along with quantile mapping statistical bias correction techniques. This step, namely NM, splits the original data into two parts - a normalized one that is bias adjusted using quantile mapping, and a residuals part that is added to the former after the bias correction. The methodology is tested and validated from several points of view, leading to some key remarks about its added value. First, it is shown that the use of the NM module results in the long-term temperature trend preservation of the mean tem- perature change, as well as of the trend in the higher and lower percentiles. Furthermore, the examination of the standard deviation temporal evolution shows that it is better retained relative to the raw data, as the exclusion of the residuals from the correction minimizes the inflation of the variance. Additionally, the inter-annual variability of the raw data is preserved relative to the compared simpler quantile mapping methods, which is an important feature for climate impact studies that involve carbon cycle simulations (Rubino et al., 2016). Another noteworthy feature of the proposed method is that the normalization is performed on an annual basis; hence, the projection period results are not affected by the length of the projection period. Nevertheless, it has to be stressed that a range of issues - such as the disruption of the physical consistency of climate variables, the mass/energy balance and the omission of correction feedback mechanisms to other climate variables (Ehret et al., 2012) - were not examined in this work, despite the existence of methods that preserve consistency between specific variables (Sippel et al., 2016). As an epilogue, bias correction cannot add further accuracy to the data but rather add usefulness to it, depending on the needs of each application. Nevertheless, it should not be underestimated that this added usefulness may obscure a deterioration of the climate change signal owing to the bias correction.

Data availability. All the underlying research data are freely accessible. The RCM data were obtained from the Earth System Grid Federation (ESGF - https://esg-dn1.nsc.liu.se/search/cordex/, Jacob et al., 2014). The E-OBS data were obtained from the European Climate Assessment \& Dataset project website (http://www. ecad.eu, Haylock et al., 2008). The HadCET temperature data were obtained from the Met Office website (https://www.metoffice.gov. uk/hadobs/hadcet/, Parker et al., 1992).

\section{The Supplement related to this article is available online at https://doi.org/10.5194/esd-8-889-2017-supplement.}

Competing interests. The authors declare that they have no conflict of interest.

Acknowledgements. The authors would like to thank Stefan Hagemann and the anonymous reviewer for their valuable comments and suggestions which improved the quality of the paper. The research leading to these results has received funding from the HELIX project of the European Union's Seventh Framework Programme for research, technological development and demonstration under grant agreement no. 603864. We acknowledge the World Climate Research Programme's Working Group on Regional Climate, and the Working Group on Coupled Modeling, former coordinating body of CORDEX and responsible panel for CMIP5. 
We also thank the climate modeling groups (listed in Table 1 of this paper) for producing and making available their model output. Finally, we acknowledge the E-OBS dataset from the ENSEMBLES EU-FP6 project (http://ensembles-eu.metoffice.com) and the data providers in the ECA\&D project (http://www.ecad.eu).

Edited by: Axel Kleidon

Reviewed by: Stefan Hagemann and one anonymous referee

\section{References}

Bürger, G., Sobie, S. R., Cannon, A. J., Werner, A. T., and Murdock, T. Q.: Downscaling Extremes: An Intercomparison of Multiple Methods for Future Climate, J. Climate, 26, 3429-3449, https://doi.org/10.1175/JCLI-D-12-00249.1, 2013.

Cannon, A. J., Sobie, S. R., and Murdock, T. Q.: Bias Correction of GCM Precipitation by Quantile Mapping: How Well Do Methods Preserve Changes in Quantiles and Extremes?, J. Climate, 28, 6938-6959, https://doi.org/10.1175/JCLI-D-14-00754.1, 2015.

Christensen, J. H., Boberg, F., Christensen, O. B., and LucasPicher, P.: On the need for bias correction of regional climate change projections of temperature and precipitation, Geophys. Res. Lett., 35, L20709, https://doi.org/10.1029/2008GL035694, 2008.

Daliakopoulos, I. N., Tsanis, I. K., Koutroulis, A. G., Kourgialas, N. N., Varouchakis, E. A., Karatzas, G. P., and Ritsema, C. J.: The Threat of Soil Salinity: a European scale review, Sci. Total Environ., 573, 727-739, 2016.

Ehret, U., Zehe, E., Wulfmeyer, V., Warrach-Sagi, K., and Liebert, J.: HESS Opinions "Should we apply bias correction to global and regional climate model data?", Hydrol. Earth Syst. Sci., 16, 3391-3404, https://doi.org/10.5194/hess-16-3391-2012, 2012.

Fischer, E. M., Rajczak, J., and Schär, C.: Changes in European summer temperature variability revisited, Geophys. Res. Lett., 39, L19702, https://doi.org/10.1029/2012GL052730, 2012.

Geisser, S.: Predictive inference, CRC press, New York, 1993.

Grillakis, M. G., Koutroulis, A. G., and Tsanis, I. K.: Climate change impact on the hydrology of Spencer Creek watershed in Southern Ontario, Canada. J. Hydrol., 409, 1-19, https://doi.org/10.1016/j.jhydrol.2011.06.018, 2011.

Grillakis, M. G., Koutroulis, A. G., and Tsanis, I. K.: Multisegment statistical bias correction of daily GCM precipitation output, J. Geophys. Res.-Atmos., 118, 3150-3162, https://doi.org/10.1002/jgrd.50323, 2013.

Grillakis, M. G., Koutroulis, A. G., Papadimitriou, L. V., Daliakopoulos, I. N., and Tsanis, I. K.: Climate-Induced Shifts in Global Soil Temperature Regimes, Soil Sci., 181, 264-272, https://doi.org/10.1097/SS.0000000000000156, 2016.

Haerter, J. O., Hagemann, S., Moseley, C., and Piani, C.: Climate model bias correction and the role of timescales, Hydrol. Earth Syst. Sci., 15, 1065-1079, https://doi.org/10.5194/hess-15-10652011, 2011.

Hagemann, S., Chen, C., Clark, D. B., Folwell, S., Gosling, S. N., Haddeland, I., Hanasaki, N., Heinke, J., Ludwig, F., Voss, F., and Wiltshire, A. J.: Climate change impact on available water resources obtained using multiple global climate and hydrology models, Earth Syst. Dynam., 4, 129-144, https://doi.org/10.5194/esd-4-129-2013, 2013.
Hansen, J. W., Challinor, A., Ines, A. V. M., Wheeler, T., and Moron, V.: Translating climate forecasts into agricultural terms: advances and challenges, Clim. Res., 33, 27-41, 2006.

Harding, R. J., Weedon, G. P., van Lanen, H. A. J., and Clark, D. B.: The future for global water assessment, J. Hydrol., 518, 186-193, https://doi.org/10.1016/j.jhydrol.2014.05.014, 2014.

Hasumi, H. and Emori, S.: K-1 Coupled GCM (MIROC) Description K-1 model developers, Tokyo, 2004.

Hawkins, E., Sutton, R., Hawkins, E., and Sutton, R.: Connecting Climate Model Projections of Global Temperature Change with the Real World, B. Am. Meteorol. Soc., 97, 963-980, https://doi.org/10.1175/BAMS-D-14-00154.1, 2016.

Haylock, M. R., Hofstra, N., Klein Tank, A. M. G., Klok, E. J., Jones, P. D., and New, M.: A European daily highresolution gridded data set of surface temperature and precipitation for 1950-2006, J. Geophys. Res., 113, D20119, https://doi.org/10.1029/2008JD010201, 2008 (data available at: http://www.ecad.eu).

Hempel, S., Frieler, K., Warszawski, L., Schewe, J., and Piontek, F.: A trend-preserving bias correction - the ISI-MIP approach, Earth Syst. Dynam., 4, 219-236, https://doi.org/10.5194/esd-4219-2013, 2013.

Hofstra, N., New, M., and McSweeney, C.: The influence of interpolation and station network density on the distributions and trends of climate variables in gridded daily data, Clim. Dynam., 35, 841-858, https://doi.org/10.1007/s00382-009-0698-1, 2010.

Huybers, P. and Curry, W.: Links between annual, Milankovitch and continuum temperature variability, Nature, 441, 329-332, https://doi.org/10.1038/nature04745, 2006.

Ines, A. V. M. and Hansen, J. W.: Bias correction of daily GCM rainfall for crop simulation studies, Agric. For. Meteorol., 138, 44-53, https://doi.org/10.1016/j.agrformet.2006.03.009, 2006.

Jacob, D., Petersen, J., Eggert, B., Alias, A., Christensen, O. B., Bouwer, L. M., Braun, A., Colette, A., Déqué, M., Georgievski, G., Georgopoulou, E., Gobiet, A., Menut, L., Nikulin, G., Haensler, A., Hempelmann, N., Jones, C., Keuler, K., Kovats, S., Kröner, N., Kotlarski, S., Kriegsmann, A., Martin, E., van Meijgaard, E., Moseley, C., Pfeifer, S., Preuschmann, S., Radermacher, C., Radtke, K., Rechid, D., Rounsevell, M., Samuelsson, P., Somot, S., Soussana, J.-F., Teichmann, C., Valentini, R., Vautard, R., Weber, B., and Yiou, P.: EUROCORDEX: new high-resolution climate change projections for European impact research, Reg. Environ. Chang., 14, 563-578, https://doi.org/10.1007/s10113-013-0499-2, 2014 (data available at: https://esg-dn1.nsc.liu.se/search/cordex/).

Klemes, V.: Operational testing of hydrological simulation models, Hydrol. Sci. J., 31, 13-24, https://doi.org/10.1080/02626668609491024, 1986.

Knutti, R.: The end of model democracy?, Clim. Change, 102, 395404, https://doi.org/10.1007/s10584-010-9800-2, 2010.

Kotlarski, S., Keuler, K., Christensen, O. B., Colette, A., Déqué, M., Gobiet, A., Goergen, K., Jacob, D., Lüthi, D., van Meijgaard, E., Nikulin, G., Schär, C., Teichmann, C., Vautard, R., Warrach-Sagi, K., and Wulfmeyer, V.: Regional climate modeling on European scales: a joint standard evaluation of the EUROCORDEX RCM ensemble, Geosci. Model Dev., 7, 1297-1333, https://doi.org/10.5194/gmd-7-1297-2014, 2014.

Koutroulis, A. G., Grillakis, M. G., Daliakopoulos, I. N., Tsanis, I. K., and Jacob, D.: Cross sectoral impacts on wa- 
ter availability at $+2{ }^{\circ} \mathrm{C}$ and $+3{ }^{\circ} \mathrm{C}$ for east Mediterranean island states: The case of Crete, J. Hydrol., 532, 16-28, https://doi.org/10.1016/j.jhydrol.2015.11.015, 2016.

Kyselý, J. and Plavcová, E.: A critical remark on the applicability of E-OBS European gridded temperature data set for validating control climate simulations, J. Geophys. Res., 115, D23118, https://doi.org/10.1029/2010JD014123, 2010.

Li, H., Sheffield, J., and Wood, E. F.: Bias correction of monthly precipitation and temperature fields from Intergovernmental Panel on Climate Change AR4 models using equidistant quantile matching, J. Geophys. Res., 115, D10101, https://doi.org/10.1029/2009JD012882, 2010.

Maraun, D.: Bias Correcting Climate Change Simulations - a Critical Review, Curr. Clim. Chang. Reports, 2, 211-220, https://doi.org/10.1007/s40641-016-0050-x, 2016.

Maraun, D., Wetterhall, F., Ireson, A. M., Chandler, R. E., Kendon, E. J., Widmann, M., Brienen, S., Rust, H. W., Sauter, T., Themeß1, M., Venema, V. K. C., Chun, K. P., Goodess, C. M., Jones, R. G., Onof, C., Vrac, M., and Thiele-Eich, I.: Precipitation downscaling under climate change: Recent developments to bridge the gap between dynamical models and the end user, Rev. Geophys., 48, RG3003, https://doi.org/10.1029/2009RG000314, 2010.

Maurer, E. P. and Pierce, D. W.: Bias correction can modify climate model simulated precipitation changes without adverse effect on the ensemble mean, Hydrol. Earth Syst. Sci., 18, 915925, https://doi.org/10.5194/hess-18-915-2014, 2014.

Nikulin, G., Bosshard, T., Yang, W., Barring, L., Wilcke, R., Vrac, M., Vautard, R., Noel, T., Gutierrez, J. M., Herrera, S., Fernandez, J., Haugen, J. E., Benestad, R., Landgren, O. A., Grillakis, M., Tsanis, I., Koutroulis, A., Dosio, A., Ferrone, A., and Switanek, M.: Bias Correction Intercomparison Project (BCIP): an introduction and the first results, EGU General Assembly Conference Abstracts, p. 2250, 2015.

Olsson, T., Jakkila, J., Veijalainen, N., Backman, L., Kaurola, J., and Vehviläinen, B.: Impacts of climate change on temperature, precipitation and hydrology in Finland - studies using bias corrected Regional Climate Model data, Hydrol. Earth Syst. Sci., 19, 3217-3238, https://doi.org/10.5194/hess-19-3217-2015, 2015.

Papadimitriou, L. V., Koutroulis, A. G., Grillakis, M. G., and Tsanis, I. K.: The effect of GCM biases on global runoff simulations of a land surface model, Hydrol. Earth Syst. Sci., 21, 4379-4401, https://doi.org/10.5194/hess-21-4379-2017, 2017.

Papadimitriou, L. V., Koutroulis, A. G., Grillakis, M. G., and Tsanis, I. K.: High-end climate change impact on European runoff and low flows - exploring the effects of forcing biases, Hydrol. Earth Syst. Sci., 20, 1785-1808, https://doi.org/10.5194/hess-20-17852016, 2016.
Parker, D. and Horton, B.: Uncertainties in central England temperature 1878-2003 and some improvements to the maximum and minimum series, Int. J. Climatol., 25, 1173-1188, https://doi.org/10.1002/joc.1190, 2005.

Parker, D. E., Legg, T. P., and Folland, C. K.: A new daily central England temperature series, 1772-1991, Int. J. Climatol., 12, 317-342, https://doi.org/10.1002/joc.3370120402, 1992 (data available at: https://www.metoffice.gov.uk/hadobs/hadcet/).

Pierce, D. W., Cayan, D. R., Maurer, E. P., Abatzoglou, J. T., Hegewisch, K. C., Pierce, D. W., Cayan, D. R., Maurer, E. P., Abatzoglou, J. T., and Hegewisch, K. C.: Improved Bias Correction Techniques for Hydrological Simulations of Climate Change, J. Hydrometeorol., 16, 2421-2442, https://doi.org/10.1175/JHM-D-14-0236.1, 2015.

Prein, A. F., Gobiet, A., Truhetz, H., Keuler, K., Goergen, K., Teichmann, C., Fox Maule, C., van Meijgaard, E., Déqué, M., Nikulin, G., Vautard, R., Colette, A., Kjellström, E., and Jacob, D.: Precipitation in the EURO-CORDEX $0.11^{\circ}$ and $0.44^{\circ}$ simulations: high resolution, high benefits?, Clim. Dynam., 46, 383412, https://doi.org/10.1007/s00382-015-2589-y, 2015.

Rubino, M., Etheridge, D. M., Trudinger, C. M., Allison, C. E., Rayner, P. J., Enting, I., Mulvaney, R., Steele, L. P., Langenfelds, R. L., Sturges, W. T., Curran, M. A. J., and Smith, A. M.: Low atmospheric $\mathrm{CO}_{2}$ levels during the Little Ice Age due to cooling-induced terrestrial uptake, Nat. Geosci., 9, 691-694, https://doi.org/10.1038/ngeo2769, 2016.

Sharma, D., Das Gupta, A., and Babel, M. S.: Spatial disaggregation of bias-corrected GCM precipitation for improved hydrologic simulation: Ping River Basin, Thailand, Hydrol. Earth Syst. Sci., 11, 1373-1390, https://doi.org/10.5194/hess-11-1373-2007, 2007.

Sippel, S., Otto, F. E. L., Forkel, M., Allen, M. R., Guillod, B. P., Heimann, M., Reichstein, M., Seneviratne, S. I., Thonicke, K., and Mahecha, M. D.: A novel bias correction methodology for climate impact simulations, Earth Syst. Dynam., 7, 71-88, https://doi.org/10.5194/esd-7-71-2016, 2016.

Teutschbein, C. and Seibert, J.: Bias correction of regional climate model simulations for hydrological climate-change impact studies: Review and evaluation of different methods, J. Hydrol., 456, 12-29, https://doi.org/10.1016/j.jhydrol.2012.05.052, 2012.

Themeß1, M. J., Gobiet, A., and Heinrich, G.: Empirical-statistical downscaling and error correction of regional climate models and its impact on the climate change signal, Clim. Change, 112, 449468, https://doi.org/10.1007/s10584-011-0224-4, 2011. 